\title{
Activity of Brazilian and Bulgarian propolis against different species of Leishmania
}

\author{
Gérzia Maria de Carvalho Machado, Leonor Laura Leon, Solange Lisboa De Castro*/+
}

Laboratório de Bioquímica de Tripanosomatídeos, Departamento de Imunologia *Laboratório de Biologia Celular, Departamento de Ultra-estrutura e Biologia Celular, Instituto Oswaldo Cruz-Fiocruz, Av. Brasil 4365, 21040-900 Rio de Janeiro, RJ, Brasil

Extracts of propolis samples collected in Brazil and Bulgaria were assayed against four Leishmania species Leishmania amazonensis, L. braziliensis, L. chagasi from the New World, and L. major from the Old World-associated to different clinical forms of leishmaniasis. The composition of the extracts has been previously characterized by high temperature high resolution gas chromatography coupled to mass spectrometry. Considering the chemical differences among the extracts and the behavior of the parasites, it was observed significant differences in the leishmanicidal activities with IC50/1 day values in the range of 2.8 to $229.3 \mu \mathrm{g} / \mathrm{ml}$. An overall analysis showed that for all the species evaluated, Bulgarian extracts were more active than the ethanol Brazilian extract. As the assayed propolis extracts have their chemical composition determined it merits further investigation the effect of individual components or their combinations on each Leishmania species.

Key words: Leishmania - leishmaniasis - propolis - chemical composition - natural products

Leishmaniasis is endemic in 88 countries of Tropical and Sub-tropical regions, affecting more than 12 million people (WHO 2004). No vaccines are available for any form of the disease, and the chemotherapy of this disease is still inadequate and expensive (Croft \& Yardley 2002). In this context, there is an intense search for potential new synthetic compounds and natural products for the treatment of leishmaniasis. In the last decades occurred a movement sometimes called "back to Nature", which in the area of drug development was accentuated by the success obtained, for example, by taxol in cancer chemotherapy and artemisinin for malaria (Newman et al. 2003). Such intensification in the search for drugs from natural sources was also observed in the area of leishmaniasis. In the literature there are several reports on the activity of a variety of crude natural extracts, especially from plants collected in tropical zones, against Leishmania species of the New World (Fournet et al. 1994, 1996, Akendengue et al. 1999, Weniger et al. 2001, Fournet \& Munoz 2002). Most of these studies were performed with L. amazonensis and L. braziliensis that cause the cutaneous form of the disease (Lainson 1983, Hepburn 2000), and as second pathology, the first species led to the diffuse cutaneous form (Garnier \& Croft 2002), and the second one to the mucocutaneous disease (Jones et al. 1987, Almeida et al. 1996); and also with $L$. chagasi the causal agent of visceral leishmaniasis (Lainson et al. 1987, Davidson 1999).

Our group has been engaged for several years in the investigation of propolis effect against pathogenic trypanosomatids, especially Trypanosoma cruzi, agent of

\footnotetext{
Finacial support: CNPq, Faperj, Papes/Fiocruz ${ }^{+}$Corresponding author: solange@ioc.fiocruz.br Received 15 August 2006

Accepted 25 October 2006
}

Chagas disease (De Castro \& Higashi 1995, Marcucci et al. 2001, Cunha et al. 2004, Dantas et al. 2005, 2006). Propolis is a resinous substance that honeybees use to fill gaps and to seal parts of the hive and is collected from different plant exudates resulting in a complex mixture containing known bioactive constituents (Bankova et al. 2000). This product possesses microbicidal, anti-inflammatory, and anti-tumoral activities, which have been associated with the presence of phenolic compounds (reviewed in De Castro 2001). We have previously determined the chemical composition as well as the analgesic and anti-inflammatory activities of a standard ethanol extract of a Bulgarian sample (Et-Blg) (Prytzyk et al. 2003, Paulino et al. 2003) and compared its activity to that of a corresponding Brazilian extract (EtBra) against $T$. cruzi and several species of fungi and bacteria of medical importance (Salomão et al. 2004). In the present work, we analyzed the effect of these extracts against different species of Leishmania.

\section{MATERIALS AND METHODS}

Propolis samples - The Bulgarian propolis (Blg) sample was collected at Burgas (Southeast Bulgaria) (Prytzyk et al. 2003) and the Brazilian one (Bra) at Mar de Espanha (state of Minas Gerais, Brazil) (Salomão et al. 2004). The exudates collected by bees in Bulgaria were mainly from buds of Populus nigra, and those in Brazil from a mixture of tropical plants. Each sample was cut in small pieces, after cooling bellow $-10^{\circ} \mathrm{C}$ and extracted with $70 \%$ ethanol $(1: 10 \mathrm{w} / \mathrm{v})$, under agitation at room temperature. After $24 \mathrm{~h}$, the extracts were filtered and evaporated to dryness under vacuum at $40^{\circ} \mathrm{C}$ and stored in a desiccator at $4^{\circ} \mathrm{C}$. The yield of the extracts was 62 and 58\% for Et-Blg and Et-Bra, respectively. Also, an acetone extract from the Bulgarian sample was obtained after extraction of the resin with hexane (1:25, $\mathrm{w} / \mathrm{v}$ ) followed by extraction of the residue with acetone at room temperature leading to Ket-Blg, obtained in a yield of $7.5 \%$. The composition of the extracts has been 
previously characterized by high temperature high resolution gas chromatography coupled to mass spectrometry (HT-HRGC-MS) (Table I) (Prytzyk et al. 2003, Salomão et al. 2004).
Parasites - Promastigote forms of L. amazonensis (strain MHOM/BR/77/LTB0016) were maintained in Schneider's Drosophila medium supplemented with $10 \%$ fetal calf serum (FCS), $\mathrm{pH} \mathrm{7.2,} \mathrm{at} 26^{\circ} \mathrm{C}$. Promastigotes

TABLE I

Chemical characterization of the Bulgarian and Brazilian propolis extracts by high temperature high resolution gas chromatography coupled to mass spectrometry

\begin{tabular}{|c|c|c|c|}
\hline \multirow[b]{2}{*}{ Compound } & \multicolumn{3}{|c|}{$\%$ area } \\
\hline & Et-Blg ${ }^{a}$ & Ket-Blg${ }^{a}$ & Et-Bra ${ }^{b}$ \\
\hline 3-Acetobutyric acid & - & - & 0.53 \\
\hline$\alpha$-Amyrin & - & - & 0.53 \\
\hline$\beta$-Amyrin & - & - & 0.93 \\
\hline$\beta$-Amyrin acetate & - & - & 0.56 \\
\hline Amyrin 3-methoxy & - & - & 0.52 \\
\hline Benzoic acid & 0.14 & $\operatorname{tr}$ & - \\
\hline Benzyl caffeate & 1.64 & 0.72 & - \\
\hline Caffeic acid & 2.61 & 6.87 & 0.57 \\
\hline Chrysin & 2.22 & 3.85 & - \\
\hline Cinnamic acid & - & - & 4.81 \\
\hline Diethyl 2-methylsuccinate & - & - & 7.00 \\
\hline 3,4-Dimethoxy-cinnamic acid & 0.37 & - & - \\
\hline 2-Ethylhexanoic acid & - & - & 1.44 \\
\hline Ethyl hydrocinnamate & - & - & 0.27 \\
\hline Ethyl indolacetate & - & - & 1.11 \\
\hline Ferulic acid & 0.40 & - & 0.40 \\
\hline Fructose & 0.36 & 10.03 & - \\
\hline Geranyl acetal & - & - & 2.99 \\
\hline Glicyrrizic acid & - & - & 1.03 \\
\hline Glucose & 0.62 & 1.22 & - \\
\hline Glycerol & 0.92 & 5.00 & - \\
\hline Hexadecanoic acid & - & - & 1.14 \\
\hline Hydrocinnamic acid & - & - & 4.48 \\
\hline Hydroxymethyl indolacetate & - & - & 2.58 \\
\hline 2-Indolcarboxylic acid & - & - & 0.35 \\
\hline Inositol & - & - & 0.39 \\
\hline Isobutylquinoline & - & - & 4.30 \\
\hline Isoferulic acid & 0.30 & - & - \\
\hline 3-Ketoadipic acid & - & - & 0.46 \\
\hline Linoleic acid & - & - & 1.30 \\
\hline Mannose & - & - & 0.66 \\
\hline Menthol & - & - & 4.00 \\
\hline Myristic acid & 0.65 & 0.95 & - \\
\hline Oleic acid & 2.33 & 0.24 & 2.63 \\
\hline Palmitic acid & 2.46 & 0.61 & - \\
\hline Palmitoleic acid & 0.87 & 0.24 & - \\
\hline Patchouli alcohol & - & - & 5.60 \\
\hline$p$-Coumaric acid & 0.60 & 0.41 & - \\
\hline Pentanedioc acid & - & - & 4.84 \\
\hline Pentenoic acid & - & - & 1.60 \\
\hline Pentenyl caffeate (isomer) & 0.74 & $\operatorname{tr}$ & - \\
\hline Pentenyl caffeate (isomer) & 1.41 & $\operatorname{tr}$ & - \\
\hline Pentenyl ferrulate (isomer) & 0.97 & $\operatorname{tr}$ & - \\
\hline Pentenyl ferrulate (isomer) & 0.79 & $\operatorname{tr}$ & - \\
\hline Phenethyl caffeate & 2.10 & 0.43 & - \\
\hline Pinobanksin 3-butanoate & 9.85 & 1.36 & - \\
\hline Pinobanksin 3-etanoate & 11.23 & 3.85 & - \\
\hline Pinobanksin 3-pentanoate & 2.75 & 0.58 & - \\
\hline Pinocembrin & 9.44 & 3.60 & - \\
\hline Pinostrobin & - & - & 1.06 \\
\hline Pinostrobin chalcone & 0.40 & - & - \\
\hline Squalene & 4.41 & - & - \\
\hline Stearic acid & 0.66 & $\operatorname{tr}$ & - \\
\hline Undecanoic acid & - & - & 2.89 \\
\hline
\end{tabular}

$a$ : Prytzyk et al. 2003; $b$ : Salomão et al. 2004. 
of L. braziliensis (MCAN/BR/98/R619), L. chagasi (MCAN/BR/97/P142), and L. major (Cão4) were grown in the same medium supplemented with $20 \%$ FCS plus $2 \%$ human urine, $\mathrm{pH} 7.2$, at $26^{\circ} \mathrm{C}$ (Howard et al. 1991, Shamsuzzaman et al. 1999). The parasites were maintained only up to five passages, in order to guarantee to perform the experiments with infective forms (Cysne-Filkelstein et al. 1998). The parasites were harvested in the late log phase of growth, which varies for each species, by centrifugation at $4000 \mathrm{rpm}$ for $10 \mathrm{~min}$ and the sediment was resuspended in the supernatant of the corresponding culture, counted in a Neubauer chamber and the concentration adjusted to $2 \times 10^{6}$ promatigotes $/ \mathrm{ml}$.

Leishmanicidal activity - Stock solutions of Et-Blg, Et-Bra and Ket-Blg were prepared in dimethylsulfoxide at $100 \mathrm{mg} / \mathrm{ml}$. A volume of $100 \mu \mathrm{l}$ of each parasite suspension $\left(2 \times 10^{5}\right.$ promastigotes) was added in 96 -well microplates to the same volume of each propolis extract, previously prepared at twice the desired concentrations in the medium employed for each species. Untreated and pentamidine isethionate-treated parasites were used as controls. The extracts were assayed in the range of 0.5 to $500 \mu \mathrm{g} / \mathrm{ml}$, with solvent concentration never exceeding $0.5 \%$, which has no deleterious effect on the parasites. The incubation was performed at $26^{\circ} \mathrm{C}$ and after $24 \mathrm{~h}$ the parasite concentration was counted and the activity of the extracts was expressed as $\mathrm{IC}_{50}$, corresponding to the concentration that leads to $50 \%$ of inhibition of promastigote proliferation.
Statistical analysis - Statistical significance $(\mathrm{p}<0.05)$ was evaluated by the ANOVA test followed by StudentNewman-Keuls, by Kruskall-Wallis or Mann-Whitney tests software SPSS for Windows.

\section{RESULTS}

The effect of the propolis extracts against different species of Leishmania is displayed in Table II. Et-Blg showed the following decreasing order of activity against the parasites: L. major $>$ L. amazonensis $>$ L. chagasi $>L$. braziliensis, always with statistical differences among the $\mathrm{IC}_{50}$ values for the four species. A similar order of activity was observed for Ket-Blg. For Et-Bra, L. major, L. chagasi, and $L$. braziliensis showed a similar sus-ceptibility to the extract, while $L$ amazonensis was the less susceptible species.

Comparing the two New World species associated to cutaneous leishmaniasis (Figs 1a,b), L. amazonensis was 7.8 times more susceptible to Et-Blg than Et-Bra, while an inverse order was observed in the case of $L$. braziliensis. Furthermore, L. chagasi, related to visceral leishmaniasis, showed a similar sensitivity to the three extracts assayed (Fig. 1c). The $\mathrm{IC}_{50} / 1$ day values for pentamidine were $4.7 \pm$ $1.6,13.4 \pm 1.4,34.2 \pm 2.5$, and $11.5 \pm 0.1 \mu \mathrm{g} / \mathrm{ml}$ for, respectively, L. amazonensis, $L$. braziliensis, L. chagasi, and L. major. For this latter species, from the Old World, the susceptibility to both Bulgarian extracts was even higher in comparison with pentamidine.
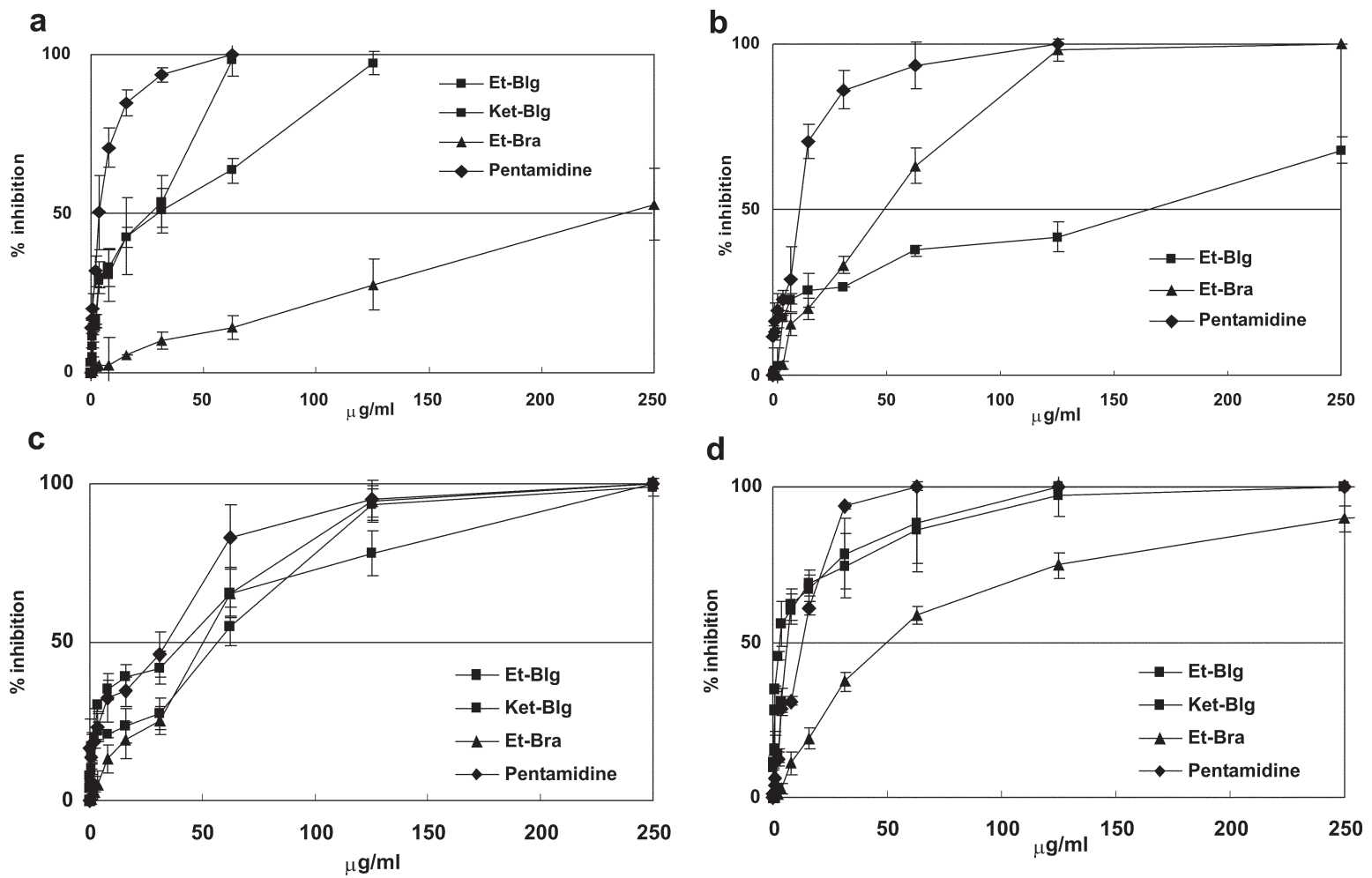

Effect of the propolis extracts Et-Blg, Ket-Blg, and Et-Bra on promastigote forms of Leishmania after 1 day at $26^{\circ} \mathrm{C}$ - a: Leishmania amazonensis; b: L. braziliensis; c: L. chagasi; d: Leishmania major. The percent of inhibition corresponds to the mean value \pm standard deviation of at least four experiments. 
TABLE II

Values of $\mathrm{IC}_{50} / 1$ day, expressed in $\mathrm{mg} / \mathrm{ml}$, for the activity of the propolis extracts on promastigote forms of different species of Leishmania

\begin{tabular}{lccrr}
\hline Extract & L. amazonensis & L. braziliensis & L. chagasi & L. major \\
\hline Et-Blg & $29.3 \pm 7.6^{a}$ & $142.2 \pm 14.5$ & $53.9 \pm 7.3$ & $7.2 \pm 1.4$ \\
Ket-Blg & $26.9 \pm 6.4$ & nd & $41.3 \pm 0.9$ & $2.8 \pm 0.3$ \\
Et-Bra & $229.3 \pm 24.2$ & $48.6 \pm 3.7$ & $49.9 \pm 4.4$ & $48.2 \pm 3.6$ \\
\hline
\end{tabular}

$a$ : mean \pm standard deviation of at least four independent experiments; nd: not determined.

\section{DISCUSSION}

Propolis samples from Bulgaria and Brazil present striking differences in their chemical composition (Marcucci \& Bankova 1999). In temperate zones, the main sources of propolis are bud exudates from different poplar trees (Populus spp.) and the microbicidal activity is associated with the presence of flavonoids and derivatives of caffeic acid (Kujungiev et al. 1999, Hegazi et al. 2000, Sawaya et al. 2002, Bankova 2005). On the other hand, in Tropical regions, like Brazil, other plant sources are presented to the bees, such as Araucaria, Baccharis, and Eucalyptus, leading to samples with a totally distinct composition, in which flavonoids are usually present in very small quantities and, the main bioactive compounds are phenolic acids, specific terpenoids, and prenylated derivatives (Kumazawa et al. 2003, Trusheva et al. 2004, Mishima et al. 2005, Teixeira et al. 2005, Pisco et al. 2006). The chemical composition of the three propolis extracts was established by HT-HRGC-MS (Prytzyk et al. 2003, Salomão et al. 2004). This technique, for separation of complex mixtures and identification of high molecular weight compounds, is an excellent alternative to classical analytical phytochemistry and a potent tool for the rapid evaluation of the composition of crude natural products, such as propolis (Pereira et al. 2000).

Et-Blg presents a predominance of flavonoids (pinostrobin, pinocembrin, chrysin, and a series of pinobanksins) corresponding to $35.9 \%$ of the total identified area, besides aromatic acids and esters and fatty acids. Ket-Blg shares several constituents with EtBlg, possessing, however, higher levels of monossacharides, and no major difference was observed between the activities of both Bulgarian extracts against the species of Leishmania assayed. The composition of Et-Bra was totally distinct from that of the other two extracts, with a very low content of flavonoids (1.1\%), corresponding to pinostrobin, besides the presence of amyrins, diethyl methyl succinate, isobutylquinoline, and geranyl acetal. The higher activity of Et-Blg against the bacteria Staphylococcus aureus, Neisseria meningitides, and Streptococcus pneumoniae, when compared to that of Et-Bra, was previously associated with the high content of flavonoids in the Bulgarian extract (Salomão et al. 2004). In the present work, a higher effect of Et-Blg was also observed for L. amazonensis (7.8X) and L. major (6.7X). However, against L. chagasi both extracts presented similar, while for L. braziliensis Et-Bra was about three times more active, indicating that other phenolic compounds, besides flavonoids, and also amyrins are probably the compounds involved in the leishmanicidal activity. As the composition of the extracts have been already determined, the next step will be the analyses of individual components and their combinations on each Leishmania species, such as the flavonoids found mainly in the Bulgarian extracts and amyrins found only in Et-Bra.

\section{ACKNOWLEDGMENTS}

To Dr Luis Moraes from Apiário Amigos da Terra (Nova Friburgo, RJ, Brazil) for donating the sample of Brazilian propolis.

\section{REFERENCES}

Akendengue B, Ngou-Milama E, Laurens A, Hocquemiller R 1999. Recent advances in the fight against leishmaniasis with natural products. Parasite 6: 3-8.

Almeida MC, Cuba-Cuba CA, Moraes MA, Miles MA 1996. Dissemination of Leishmania (Viannia) braziliensis. J Comp Pathol 115: 311-316.

Bankova VS 2005. Chemical diversity of propolis and the problem of standardization. J Ethnopharmacol 100: 114-117.

Bankova VS, De Castro SL, Marcucci MC 2000. Propolis: recent advances in search on chemistry and plant origins. Apidologie 31: 3-15.

Croft SL, Yardley V 2002. Chemotherapy of leishmaniasis. Curr Pharm Design 8: 319-342.

Cunha IBS, Salomão K, Shimizu M, Bankova VS, Custódio AR, De Castro SL, Marcucci MC 2004. Anti-trypanosomal activity of Brazilian propolis from Apis mellifera. Chem Pharm Bull 52: 602-604.

Cysne-Filkelstein L, Temporal RM, Alves F, Leon LL 1998. Leishmania amazonensis: long-term cultivation of axenic amastigotes is associated to metacyclogenesis of promastigotes. Exp Parasitol 89: 58-62.

Dantas AP, Olivieri BP, Gomes FHM, De Castro SL 2005. Treatment of Trypanosoma cruzi-infected mice with propolis promotes changes in the immune response. $J$ Ethnopharmacol 103: 187-193.

Dantas AP, Salomão K, Barbosa HS, De Castro SL 2006. The effect of Bulgarian propolis against Trypanosoma cruzi. Mem Inst Oswaldo Cruz 101: 207-211.

Davidson RN 1999. Visceral leishmaniasis in clinical practice. J Infec Dis 39: 112-116. 
De Castro SL 2001. Propolis: Biological and pharmacological activities. Therapeutic uses of this bee-product. Ann Rev Biomed Sci 3: 49-83.

De Castro SL, Higashi KO 1995. Effect of different formulations of propolis on mice infected with Trypanosoma cruzi. $J$ Ethnopharmacol 46: 55-58.

Fournet A, Munoz V 2002. Natural products as trypanocidal, antileishmanial and antimalarial drugs. Curr Top Med Chem 2: 1215-1237.

Fournet A, Barrios AA, Muñoz V 1994. Leishmanicidal and trypanocidal activities of Bolivian medicinal plants. J Ethnopharmacol 41: 19-37.

Fournet A, Ferreira ME, Rojas-De-Arias A, Torres-De-Ortiz S, Fuentes S, Nakayama H, Schinini A, Hocquemiller R 1996. In vivo efficacy of oral and intralesional administration of 2substituted quinolines in experimental treatment of new world cutaneous leishmaniasis caused by Leishmania amazonensis. Antimicrob Agents Chemother 40: 2447-2451.

Garnier T, Croft SL 2002. Topical treatment for cutaneous leishmaniasis. Curr Opin Investigat Drugs 3: 538-544.

Hegazi AG, Abd-El-Hady FK, Abd-Allah FA 2000. Chemical composition and antimicrobial activity of European propolis. Zeit Naturforsch 55C: 70-75.

Hepburn NC 2000. Cutaneous leishmaniasis. Clin Exper Dermatol 25: 363-370.

Howard MK, Pharoah MM, Ashall F, Miles MA 1991. Human urine stimulates growth of Leishmania in vitro. Trans $R$ Soc Trop Med Hyg 85: 477-479.

Jones TC, Johnson Jr WD, Barretto AC, Lago E, Badaro R, Cerf B, Reed SG, Netto EM, Tada MS, Franca TF 1987. Epidemiology of American cutaneous leishmaniasis due to Leishmania braziliensis braziliensis. J Infect Dis 156: 73-83.

Kujungiev A, Tsvetkova I, Serkedjieva Y, Bankova VS, Christov R, Popov S 1999. Antibacterial, antifungal and antiviral activity of propolis of different geographic origin. $J$ Ethnopharmacol 64: 235-240.

Kumazawa S, Yoneda M, Shibata I, Kanaeda J, Hamasaka T, Nakayama T 2003. Direct evidence for the plant origin of Brazilian propolis by the observation of honeybee behavior and phytochemical analysis. Chem Pharm Bull 51: 740-742.

Lainson R 1983. The American leishmaniasis: some observations on their ecology and epidemiology. Trans $R$ Soc Trop Med Hyg 77: 569-596.

Lainson R, Shaw JJ, Silveira FT, Braga RR 1987. American visceral leishmaniasis: on the origin of Leishmania (Leishmania) chagasi. Trans $R$ Soc Trop Med Hyg 81: 517.

Marcucci MC, Bankova VS 1999. Chemical composition, plant origin and biological activity of Brazilian propolis. Curr Top Phytochem 2: 115-123.

Marcucci MC, Ferreres F, Garcia-Viguera C, Bankova VS, De Castro SL, Dantas AP, Valente PH, Paulino N 2001. Phenolic compounds from Brazilian propolis with pharmacologi- cal activities. $J$ Ethnopharmacol 74: 105-112.

Mishima S, Ono Y, Araki Y, Akao Y, Nozawa Y 2005. Two related cinnamic acid derivatives from Brazilian honey bee propolis, baccharin and drupanin, induce growth inhibition in allografted sarcoma S-180 in mice. Biol Pharm Bull 28: 10251030.

Newman DJ, Cragg GM, Snader KM 2003. Natural products as sources of new drugs over the period 1981-2002. J Nat Prod 66: 1022-1037.

Paulino N, Dantas AP, Bankova VS, Longhi DT, Scremin A, De Castro SL, Calixto JB 2003. Bulgarian propolis induces analgesic and anti-inflammatory effects in mice and inhibits in vitro contraction of airway smooth muscle. J Pharmacol Sci 93: 307-313.

Pereira AS, Norsell M, Cardoso JN, Aquino-Neto, FR, Ramos MFS 2000. Rapid screening of polar compounds in Brazilian propolis by high-temperature high-resolution gas chromatography-mass spectrometry. J Agr Food Chem 48: 5226-5230.

Pisco L, Kordian M, Peseke K, Feist H, Michalik D, Estrada E, Carvalho J, Hamilton G, Rando D, Quincoces J 2006. Synthesis of compounds with antiproliferative activity as analogues of prenylated natural products existing in Brazilian propolis. Eur J Med Chem 41: 401-407.

Prytzyk E, Dantas AP, Salomão K, Pereira AS, Bankova VS, De Castro SL, Aquino-Neto FR 2003. Flavonoids and trypanocidal activity of Bulgarian propolis. $J$ Ethnopharmacol 88 : 189-193.

Salomão K, Dantas AP, Borba CM, Campos LC, Machado DG, Aquino Neto FR, De Castro SL 2004. Chemical composition and microbicidal activity of extracts from Brazilian and Bulgarian propolis. Lett Appl Microbiol 38: 87-92.

Sawaya ACHF, Palma AM, Caetano FM, Marcucci MC, Cunha IBS, Araújo CEP, Shimizu MT 2002. Comparative study of in vitro methods used to analyse the activity of propolis extracts with different compositions against species of Candida. Lett Appl Microbiol 35: 203-207.

Shamsuzzaman SM, Furuya M, Korenaga M, Imamura K, Hashiguchi Y 1999. Use of urine samples from healthy humans, nephritis patients or other animals as an alternative to fetal calf serum in the culture of Leishmania (Leishmania) donovani in vitro. Ann Trop Med Parasitol 93: 613-620.

Teixeira EW, Negri G, Meira RM, Message D, Salatino A 2005. Plant origin of green propolis: bee behavior, plant anatomy and chemistry. Evid-Based Complement Alternat Med 2: 85-92.

Trusheva B, Popova M, Naydenski H, Tsvetkova I, Rodriguez JG, Bankova VS 2004. New polyisoprenylated benzophenones from Venezuelan propolis. Fitoterapia 75: 683-689.

Weniger B, Robledo S, Arango GJ, Deharo E, Aragon R, Muñoz V, Callapa J, Lobstein A, Anton R 2001. Antiprotozoal activities of Colombian plants. J Ethnopharmacol 78: 193-200.

WHO 2004. Le-ishmaniasis [http:/www.who.int/tdr/diseases/ leish/]. 